\title{
Renewable Resources Future and Awareness in Saudi Arabia, Solar Photovoltaic as a Model
}

\author{
Faten Dhawi \\ Biotechnology Department, King Faisal University, AlHofuf, AlAhsa, KSA \\ Email: dr.faten.dhawi@gmail.com, falmuhanna@kfu.edu.sa
}

How to cite this paper: Dhawi, F. (2018) Renewable Resources Future and Awareness in Saudi Arabia, Solar Photovoltaic as a Model. Low Carbon Economy, 9, 101-108. https://doi.org/10.4236/lce.2018.94008

Received: November 16, 2018

Accepted: December 17, 2018

Published: December 20, 2018

Copyright $\odot 2018$ by author and Scientific Research Publishing Inc. This work is licensed under the Creative Commons Attribution International License (CC BY 4.0).

http://creativecommons.org/licenses/by/4.0/

\begin{abstract}
The global awareness regarding economy expansion and environmental preservation in the same time made the solar energy investment a vivid topic nowadays more than before. The solar energy project or the new Saudi oil made by the crown prince Mohammad bin Salman Al Saud was the focus of the current study. We designed the questionnaire with three categories to assess citizens of Saudi Arabia awareness about solar energy represented by photovoltaic system. The responses collected electronically from 424 respondents ranged between 18 - 41 years old to examine their awareness and acceptance of the solar system. The results showed a positive tendency of solar panel installment and use instead of electricity as source of energy. The respondents' confidence of photovoltaic use ability to reduce electricity bills was positive. Moreover, the Saudi public awareness and approval of electricity bills regulation were in agreement with the government policy. Around 30\% of respondents thought that solar energy is the sole source of energy where they resident. While $75 \%$ of respondents thought, they might get greater benefit from solar energy in comparison of the other renewable resources as wind and earth energy. The study emphasized the great awareness of Saudi public views analogues with the global trend and energy shift. The Photovoltaic (PV) system will be the vital investment in Saudi Arabia near future with great approval of public and government system.
\end{abstract}

\section{Keywords}

Solar, Renewable, Energy, Electricity

\section{Introduction}

Countries worldwide consider renewable resources to contribute to reduction of global warming crisis and increase income. There has been growing interest in using solar energy to reduce reliance on electricity [1]. Saudi Electric Company 
started a policy to encourage solar energy installment and use via Photovoltaic (PV) system. Saudi Arabia unique geographical location and large area with mostly sunny climate condition made it a great candidate to invest in solar energy. The solar energy project or the new Saudi oil made by the crown prince Mohammad bin Salman bin Abdulaziz Al Saud. The Saudi solar energy project partnered with Softbank planned to provide the solar energy at an unbeatable price and a big profit, while reducing electricity prices for citizens. The solar investment will open the Saudi market for citizens' investment, services and job opportunities. The foundation of King Salman Energy Park (Spark), managed by Aramco with investments worth around USD 1.6 billion (SAR6 billion) will enhance the level of economic diversification and support the growth of the private sector. The Council of Ministers approved the establishment of the King Salman Energy City (SPARK) in the Eastern Province. The Council also approved Saudi Aramco's mandate to establish a company to develop the city's infrastructure, manage its fixed assets and establish a company to operate, manage and maintain the city Operator. The city is located at the heart of the energy-related business between Dammam and Al-Ahsa, making it the third industrial city in Dammam. The city total area of 50 square kilometers, covers the first phase of 12 square kilometers. The city, which is being developed and operated by Aramco in partnership with the Saudi Industrial Cities and Technology Corporation (MODON), is enabling the supply chain associated with industries and services supporting the energy sector in the region and the Kingdom. The sustainability of investments guaranteed via providing an excellent infrastructure and an attractive environment for global investors, as well as providing integrated services. Aramco has initiated the establishment of the city and conducted studies and surveys with major and global suppliers. These efforts identified a number of key components to create an integrated and sustainable work environment that matches the best global centers [2].

The government of Saudi Arabia announced plans to build a solar project with 200 gigawatts (GW) by 2030 . The project will cost $\$ 200$ billion to build the world's largest solar project. The massive development plans of solar energy system in Saudi Arabia are to replace oil as energy sole source. Softbank's Son said the $200 \mathrm{GW}$ of solar would reduce the electricity cost by $\$ 40$ billion while creating 100,000 jobs [3]. The current study used a questionnaire as an assessment tool to measure public awareness and approval of using renewable resources in Saudi Arabia specifically photovoltaic (PV) to reduce traditional energy use.

\section{Material and Methods}

The study established based on descriptive analysis for questionnaire scored for 424 respondents. The questionnaire consisted of 13 questions and involved three categories to assess citizens of Saudi Arabia awareness about solar energy represented by photovoltaic use and other renewable resources to lower electricity bills. The arithmetic means and standard deviations for the participants' response computed for multiple dimensions for questionnaire further assessment. 
About 11 questions scored as Likert-scale and contained five choices of "Strongly Agree (4.21 - above), Agree (3.41 - 4.2), Neutral (2.61 - 3.4), Disagree (1.81 2.60), and Strongly Disagree (1 - 1.8) [4]. While, two questions scored as four choices solar energy, wind energy, earth energy and all sources. Throughout the questionnaire, the participants asked to rate their responses regarding four subcategories as follow:

1) The overall tendency of installment of solar panel to reduce electricity bill;

2) The confidence of photovoltaic use ability to reduce electricity charge;

3) The awareness and approval of electricity bills regulation;

4) The suitable energy source where the respondents live.

\section{Statistical Analysis}

The validity and reliability of the method tested using SPSS 16 . The Cronbach Alpha test was run for the total number of instrument's' questionnaire and scored at 0.66 that represents a high level of reliability. Moreover, the validity of the instrument's items calculated through Pearson score.

\section{Results}

The global trend is toward the renewable energy resources and Saudi Arabia is no exception. Although Saudi Arabia has the world's highest reserves for two energy sources, oil and natural gas [5]. There are many reasons that made Saudi Arabia plan to join the advanced world countries regarding energy resources, which include the global shift toward ecofriendly energy, to reduce global warming and to expand economic resources. Hence, the Saudi government announced plans to build a solar project with 200 gigawatts (GW) by 2030. To examine the public awareness on the solar energy utilization and investment we performed an electronic survey and recorded from 424 respondents. The questionnaire consisted of 13 questions scored responses of 424 individuals. The descriptive statistics in the form of arithmetic means and standard deviations for the participants computed for the multiple dimensions that been assessed through the questionnaire (Table 1). The questionnaire demographics showed that respondents' age 94\% were from 18 - 4lyears old. The respondents' demographics youth age group explained by the nature of electronic survey that are mainly accessible by ages of 18 - 41 in Saudi Arabia. The results showed a tendency of agreement of Saudi public opinion toward the government encourage of solar panel installment. In addition, around more than $60 \%$ of the public agreed of the solar panel installment ability to reduce their electricity bills or make it moderate. Whereas, the public showed a neutral response regarding the question "the consumption of regular electricity will not be affected by the presence of photovoltaic counter". Thus, public opinion is welcoming of the Saudi government introduction of solar energy (Table 1). The study emphasized the great awareness of Saudi public views analogues with the global trend and energy shift. However, the respondents use to photovoltaic system conditioned on 
Table 1. The participants' responses regarding three categories of questions related to solar energy use represented by installment of solar panel and photovoltaic use instead of electricity and bills reduction.

1) The overall tendency of solar panel installment to reduce electricity bill

\begin{tabular}{lcccc}
\hline Statement & N & Mean & Std. Deviation Overall Tendency \\
\hline $\begin{array}{l}\text { I would like to install two counters at home for the old electrical grid, the second to } \\
\text { regulate the consumption process and calculate the consumption of photovoltaic }\end{array}$ & 424 & 4.19 & 0.95
\end{tabular}

solar panels

2) The confidence of photovoltaic use ability to reduce electricity bills

\section{Statement}

I expect that the consumption of ordinary electricity will be lower with the photovoltaic counter

I expect that the consumption of regular electricity will not be affected by the presence of photovoltaic counter

I expect that the average electricity consumption will be moderate with the photovoltaic solar panel

I expect that the consumption of ordinary electricity will be lower with the photovoltaic counter

\section{3) The awareness and approval of electricity bills regulation}

\section{Statement}

In the event that the customer consumes less electricity than the photovoltaic counter, the customer will pay only the regular network meter fee, and the monthly surplus of the customer's output will be calculated at the end of each year

If the power consumption of solar panels is equal to the customer's consumption: the customer will only pay an invoice for the standard network meter

In the event that the customer's consumption is higher than the solar panels there will be additional consumption by the regular network, which will result in a bill for the normal network with the consumption value plus the meter charges

$\begin{array}{cccc}\text { N } & \text { Mean } & \text { Std. Deviation Overall Tendency } \\ 424 & 4 & 0.94 & \text { Agree } \\ 424 & 2.76 & 1.16 & \text { Neutral } \\ 424 & 3.65 & 1.06 & \text { Agree } \\ 424 & 4 & 0.94 & \text { Agree } \\ & & & \\ \text { N } & \text { Mean } & \text { Std. Deviation Overall Tendency } \\ 424 & 4.06 & 0.97 & \text { Agree } \\ & & & \text { Agree } \\ 424 & 4.06 & 0.93 & \\ & & & \end{array}$

decreasing electricity bills as trade-offs associated with storing solar energy. However, the photovoltaic typical system in many countries works on sending the energy to utility grid [1]. In a sunny country like Saudi Arabia, most of the respondents (over 75\%) thought of the sun as the source of energy where they live. Whereas, most of the respondents thought that all the sustainable energy sources (wind-sun-earth) might substitute electricity (Figure 1). The current renewable energy resources status in Saudi Arabia represented in Figure 2, where most respondents assumed the solar energy feasibility where they lived considering the sunny country nature. The government projects related to solar energy shown in Figure 2. The Saudi Arabia capital city (Riyadh) has two photovoltaic (PV) projects, one with 3.5 MW and the other has 1.8 MW. The smallest PV project is located in the Saudi Farasan Island that has $500 \mathrm{KW}$. While, King Abdullah University of Science and Technology (KAUST), at the city of Thuwl has it is own power of PV with $2 \mathrm{MW}$, whereas, the highest power comes from concentrated solar power (CSP) with $600 \mathrm{MW}$ in Duba. While, Saudi Arabia current projects involved photovoltaic system is in Dhahran with $10 \mathrm{MW}$ size and in progress the greatest PV power in Sakaka with 300 MW and the smallest in Tabuk with 1 MW. The only wind renewable source located in Tabul 


\section{Where I live I expect more benefit from}

the natural energy source derived from?

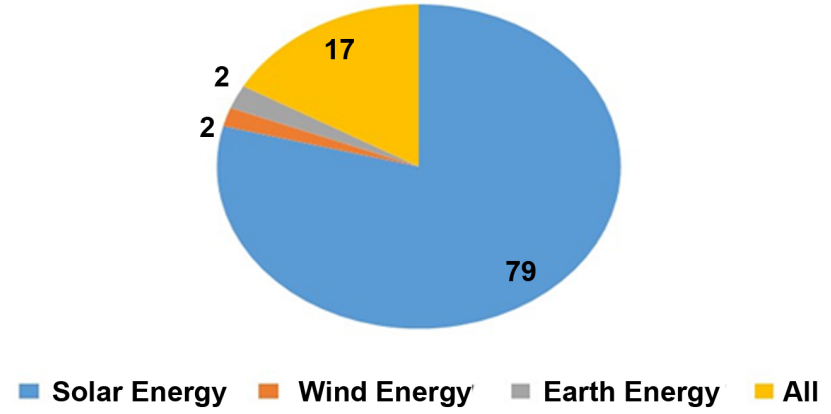

(a)

\section{What are the natural energy sources that can be used as an alternative to electricity?}

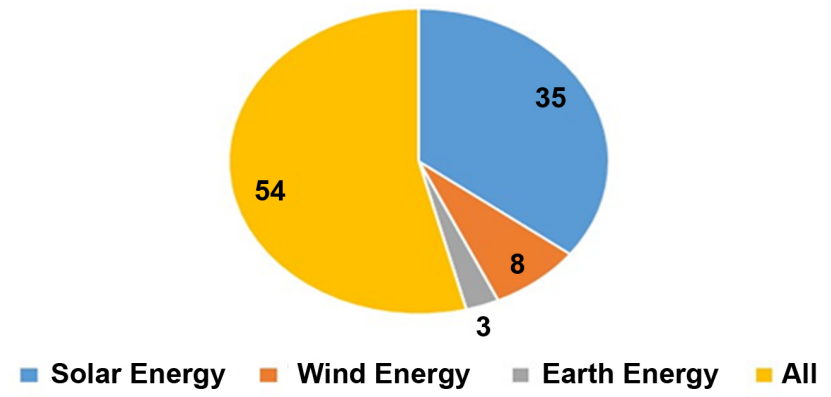

(b)

Figure 1. The respondents answering questions regarding (a) the available natural source of energy where they lived and (b) the alternative energy sources to replace electricity (the pie charts labeled numbers represented percentage of the respondents total number).

named Midyan wind, with power of $400 \mathrm{MW}$. Thus, the PV system will be a vital investment in Saudi Arabia near future with great approval of public and government system in case of assuring electricity bill reduction and solar energy tradeoff system (Figure 2).

\section{Conclusion}

The global warming resulted from oil energy and carbon emission in addition to economic necessity for various investments redirects Saudi Arabia public and government figures toward the renewable resources use and investment. The use of crude oil is not cost effective anymore, considering the environmental and the refining cost. The current study aimed to assess the citizens' acceptance and awareness of solar energy use represented by photovoltaic system (PV). The respondents showed a significant confidence of photovoltaic use ability to reduce electricity bills and the public opinion in agreement with renewable resources use via solar, wind or earth energy. The sunny nature of Saudi Arabia reflected on the public prescriptive of seeing the solar energy or PV as a potential 


\section{Saudi Arabia Renewable Future, Resources and Awareness}

\section{Photovoltaic as a Model}

By: Faten Dhawi

King Faisal University, Saudi Arabia

Where I live in Saudi Arabia I expect more benefit from the natural energy source derived from?

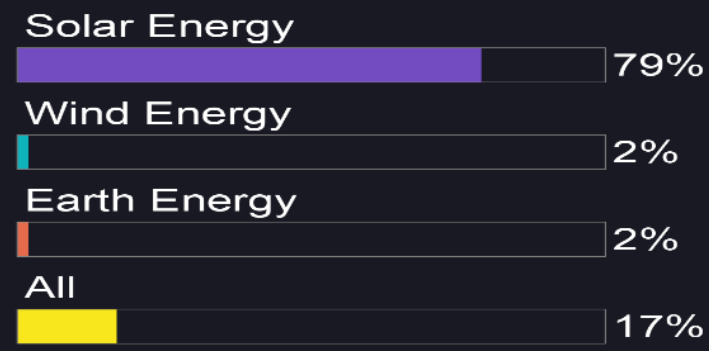

\section{Current \\ Renewable Energy Projects in Saudi Arabia}

\begin{tabular}{|c|c|c|c|c|}
\hline Project & Technology & Status & Size & Location \\
\hline $\begin{array}{l}\text { SEC-Duba Integrated Solar } \\
\text { Combined Cycle (ISCC) Power } \\
\text { Plant Phase I }\end{array}$ & CSP & Execution & $\begin{array}{l}600 \mathrm{MW} \\
\text { (CSP:20-30 MW) }\end{array}$ & Duba \\
\hline Saudi ARAMCO - KAPSARC & PV & Complete & $3.5 \mathrm{MW}$ & Riyadh \\
\hline KAPSARC II & PV & Complete & $1.8 \mathrm{MW}$ & Riyadh \\
\hline SEC - Farasan Island Solar Project & PV & Complete & $500 \mathrm{~kW}$ & Farasan IsI. \\
\hline KAUST & PV & Complete & $2 \mathrm{MW}$ & Thuwal \\
\hline North Park & PV & Complete & $10 \mathrm{MW}$ & Dhahran \\
\hline Tabuk KJC CPV & PV & Execution & $1 \mathrm{MW}$ & Tabuk \\
\hline ACWA Power-Sakaka PV & PV -25 years PPA** & Execution & $300 \mathrm{MW}$ & Sakaka \\
\hline REPDO - Midyan & Wind -20 years PPA: & RFQ & $400 \mathrm{MW}$ & Tabul \\
\hline
\end{tabular}

Saudi Arabia is implementing a net metering scheme which is available for public use from August 2017

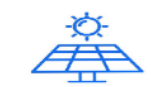

Private power generation
Lack imported from the utility grid

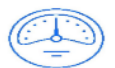

Excess exported to the utility grid

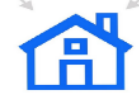

Private power consumption

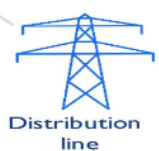

line

Figure 2. A graphical abstract of Saudi Arabia renewable resources and awareness. 
source of energy. The new Saudi oil expected to revolutionize the economy and public awareness of energy use rationalization. The only shortcoming is that PV system is still immature and people need to learn more about it to utilize the maximum level.

\section{Acknowledgements}

I would like to thank Dr. Ahmed Alrowaished at MSDR and Talal Albaqami at Ministry of Energy and Industry for insight and suggestions.

\section{Ethics Approval and Consent to Participate}

Electronic consent was obtained from the respondents as part of the questionnaire. The method used is approved by King Faisal University.

\section{Consent for Publication}

Not applicable.

\section{Availability of Data and Materials}

All data generated or analyzed during this study are included in this published article.

\section{Funding}

No fund was obtained for the current study.

\section{Authors' Contributions}

All the work in the current study is conducted by the sole author.

\section{Author Information}

Faten Dhawi Almuhanna, used the publication authorship name as Faten Dhawi, Assistant Professor in Biochemistry and Molecular Biology, Biotechnology Department, College of Agriculture and Food Science, King Faisal University, Alhofuf, Al-Ahsa, Saudi Arabia.

\section{Conflicts of Interest}

The author declares no competing interests.

\section{References}

[1] Fares, R.L. and Webber, M.E. (2017) The Impacts of Storing Solar Energy in the Home to Reduce Reliance on the Utility. Nature Energy, 2, Article Number: 17001. https://doi.org/10.1038/nenergy.2017.1

[2] https://www.saudiaramco.com/en/news-media/news/2018/king-salman-energy-par $\mathrm{k}$

[3] Cunningham, N. (2018) Building the World's Largest Solar Project. https://oilprice.com/Alternative-Energy/Solar-Energy/Building-The-Worlds-Larges 
t-Solar-Project.html

[4] Vagias, W.M. (2006) Likert-Type Scale Response Anchors. Clemson International Institute for Tourism \& Research Development, Department of Parks, Recreation and Tourism Management, Clemson University.

[5] Al-Maamary, H.M., Kazem, H.A. and Chaichan, M.T. (2017) Renewable Energy and GCC States Energy Challenges in the 21st Century: A Review. International Journal of Computation and Applied Sciences, 2, 11-18. https://doi.org/10.24842/1611/0018

\section{Abbreviations}

Photovoltaic (PV)

Concentrated solar power (CSP)

King Salman Energy City (SPARK) 